\title{
Development of micro-scale joints in volcanic rocks under thermal stress
}

\author{
Susanta Kumar Samanta \\ Department of Geological Sciences, Jadavpur University, Calcutta 700 032, India \\ e-mail: susanta_ju@hotmail.com
}

Petrographic studies of samples of the Rajmahal basalt reveal a variety of microscopic joints within phenocrysts, which seem to have developed under the influence of thermal stresses during cooling. The theoretical analysis shows that:

- thermal stresses develop in a system only under unsteady state of cooling,

- the stresses responsible for the development of joints are tensile in nature, and

- the magnitude of stresses increases with increasing rates of cooling.

In order to understand the effects of cooling rate on the mode of jointing, analogue model experiments were performed by quenching melt films of organic, crystalline materials under varying cooling conditions. In experiments, non-branching linear joints developed at relatively lower rates of cooling by a process of sub-critical crack propagation. On the other hand, at higher rates of cooling the mechanism of crack propagation was essentially supercritical leading to the development of branching joints.

\section{Introduction}

In rocks, micro-scale joints are often observed within large crystals floating in a fine-grained matrix. Intragranular joints in metamorphic rocks usually develop during upliftment and consequential volume expansion (e.g. Harley 1989; Ji et al 1997). In contrast, such joints in volcanic rocks form as a result of non-uniform volume contraction during cooling. Development of joints in a cooling rock system is essentially a consequence of the development of thermal stress (Spry 1962; Macdonald 1968; Peck and Minakami 1968; Moore and Sibson 1978).

Petrographic observations of the samples of the Rajmahal Trap reveal that a variety of joints may preferentially develop within the phenocrysts in response to thermal stresses during cooling. The purpose of this paper is to present:

- a description of different types of intragranular joints observed in the samples of Rajmahal vol- canics that seemingly have formed under thermal stresses,

- a theoretical formulation of the physical constraints leading to development of thermal stresses in a cooling system, and

- results of the analog model experiments on the formation of different types of micro-scale, thermal stress induced joints under varying cooling conditions.

\section{Micro-scale joints in the Rajmahal volcanics}

To study the micro-scale joints in rock systems, fresh samples of olivine basalt were chosen from the Rajmahal Trap of eastern India. The rocks consist of phenocrysts of olivine, clino-pyroxene (augite) and plagioclase floating in a fine-grained matrix (figure 1). The phenocrysts show diverse types of intragranular joints, whereas the matrix

Keywords. Tensile stress; jointing; crack propagation; cooling rate. 


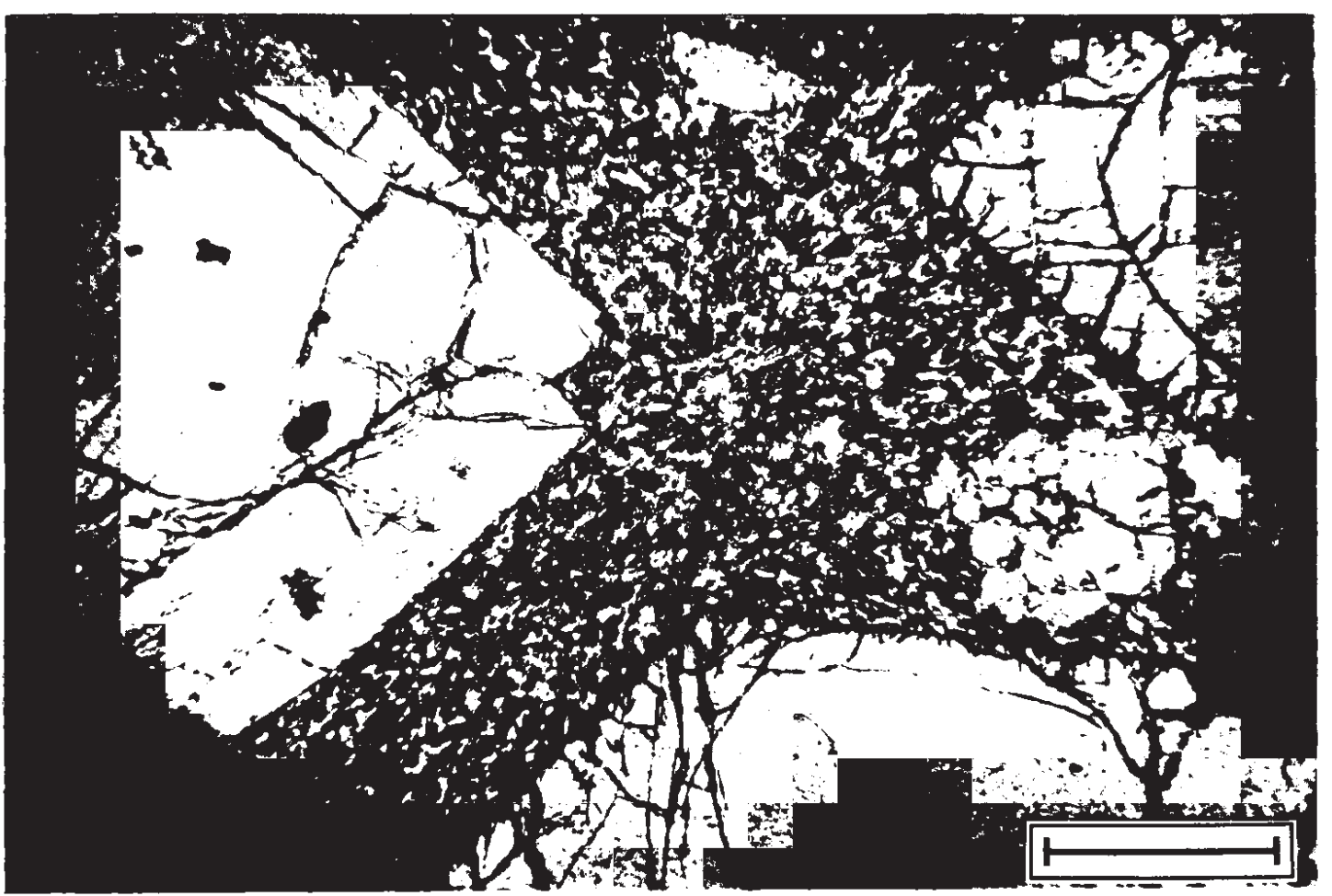

Figure 1. General petrographic character of the Rajmahal basalt showing large, euhedral phenocrysts of olivine floating in a fine-grained matrix of pyroxene and feldspar. Note different types of joints within the phenocrysts. Plane polarized light. Scale bar $=0.4 \mathrm{~mm}$.

is intact. The Rajmahal Trap is absolutely undeformed (Ball 1877) and the intragranular joints do not define any preferred orientation with respect to an external coordinate system, indicating that the joints are not products of tectonic processes. Instead, they could reflect development of thermal stresses within a cooling lava flow. The textural characteristics, e.g., crystal growth pattern, and occurrence of phenocrysts in a fine-grained matrix, also suggest sudden quenching of magma containing early-formed crystals. In the following paragraphs different types of joints observed in the phenocrysts of olivine, pyroxene and plagioclase are described separately.

Sets of both linear and curvilinear joints occur in large phenocrysts of olivine. Linear joints are of two types: (i) Minor joints that occur all along the periphery, do not extend inside the grain, and remain everywhere at high angles to the grainmatrix interface (figures 2a and 3b). (ii) Major joints that transect across a whole grain (figures $2 \mathrm{a}$ and b). On prismatic sections, there may be traces of two orthogonal sets of major joints one of, which is parallel to the cleavage (figure $2 \mathrm{~b}$ ). The crystallographic dispositions of the major joint sets are shown in figure 4(a). Curvilinear joints are quasiconcentric about the center of a grain, localized in its peripheral part (figures $2 \mathrm{c}$ and $2 \mathrm{~d}$ ). The curvature of the joints may gradually decrease towards the core of the grain and eventually may become linear (figure 2c).

Pyroxene phenocrysts dominantly show a single set of major, thoroughgoing, linear joints oriented at an angle to the cleavage sets (figure 3a), in addition to the linear and curvilinear joints localized in the peripheral part. The sectional angle between the joint and the cleavage varies from $25^{\circ}$ on prismatic sections (figure $3 \mathrm{~b}$ ) to $45^{\circ}$ on basal sections (figure 3a). The crystallographic disposition of the major joint set is shown in figure 4(b). The major joints may slightly change their orientation abruptly along the length (figure $3 \mathrm{~b}$ ). In some crystals major, linear joints are associated with peripheral, curved joints (figure 3c).

Plagioclase phenocrysts occur as long prismatic grains. The joints in them are generally linear, parallel and regularly spaced, transecting either individual lamellae (figure 5a) or the entire width of the grain (figure 5b). They are generally oriented at a right angle to the long direction of the grain (figure 5a). Some of the plagioclase grains, however, show joints with an oblique orientation (figure 5b).

The inequigranular, porphyritic texture of the Rajmahal basalts, intragranular occurrence of the joints and absence of tectonic deformations in the Rajmahal Trap indicate that jointing has taken place in response to thermal stresses during cooling. A phenocryst hosted in a matrix experiences 

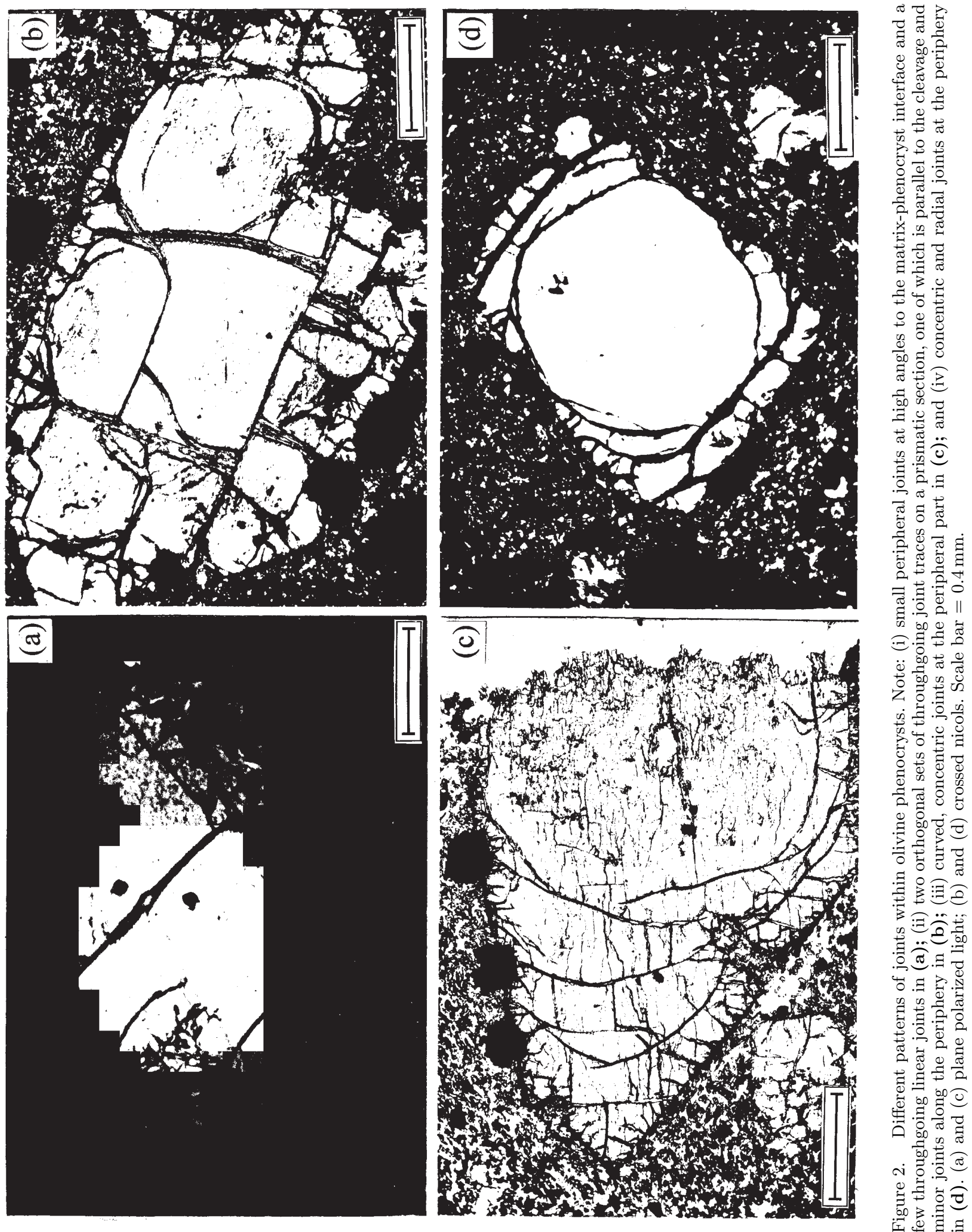

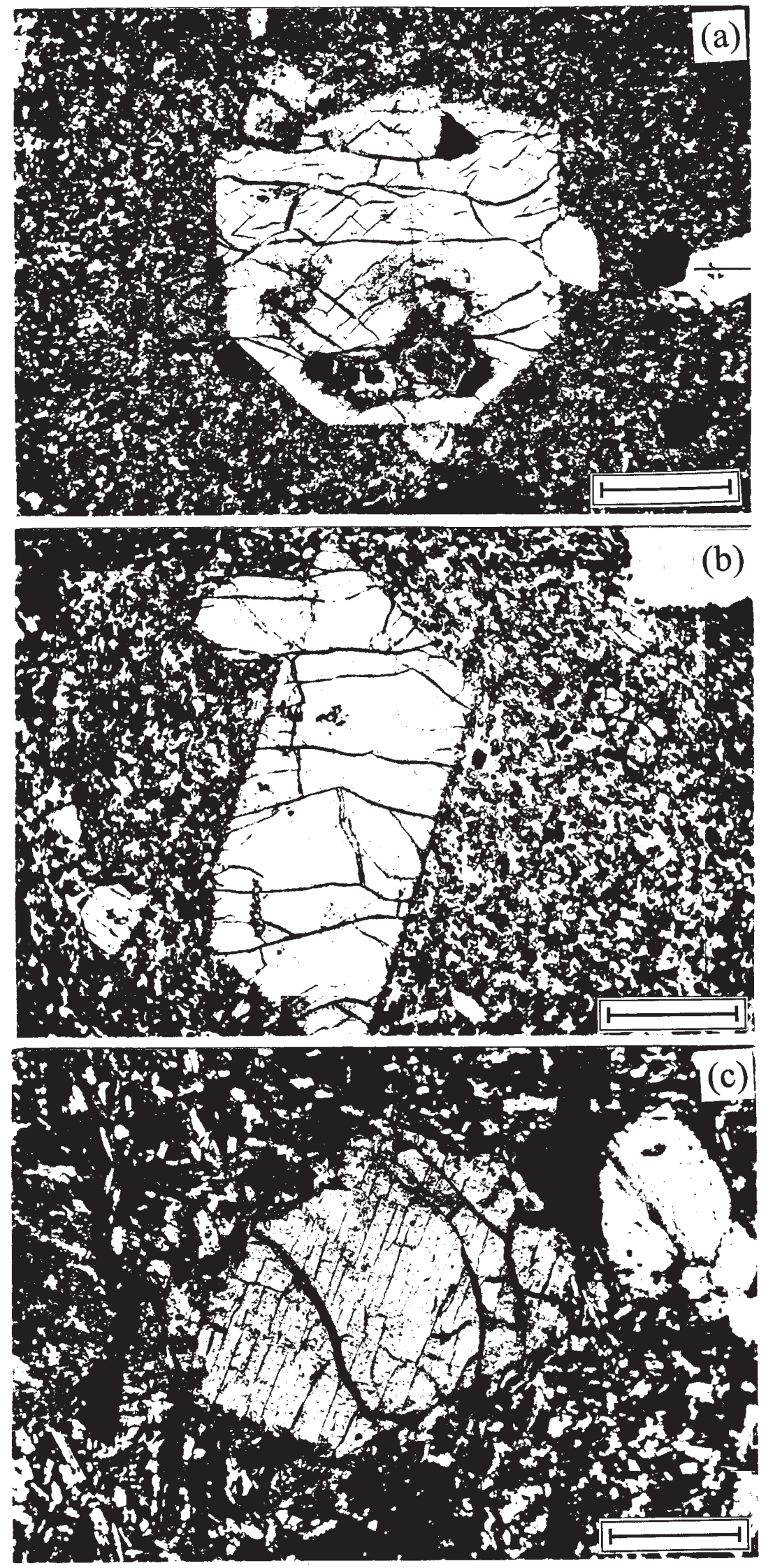

Figure 3. Joints within pyroxene phenocrysts. (a): A throughgoing linear joint set bisecting two sets of cleavage traces on a basal section. (b): Joints on a prismatic section; note small peripheral joints roughly at high angles to the grain-matrix interface, and a throughgoing quasi-linear joint set transecting the cleavage traces. (c): Curvilinear, quasi-concentric joints in the peripheral part (right) along with a throughgoing quasi-linear joint (left). (a) and (c) crossed nicols; (b)plane polarized light. Scale bar $=0.6 \mathrm{~mm}$. 


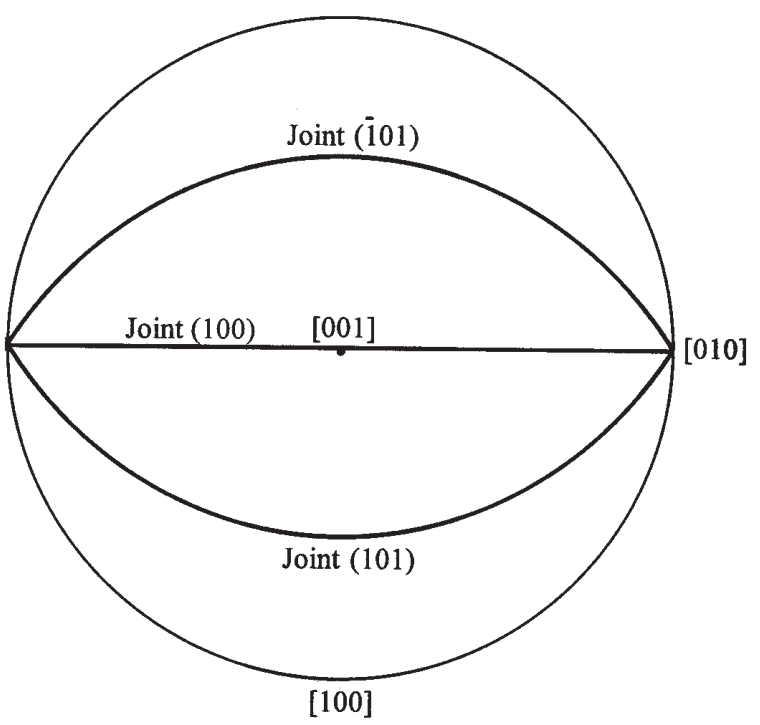

(a)

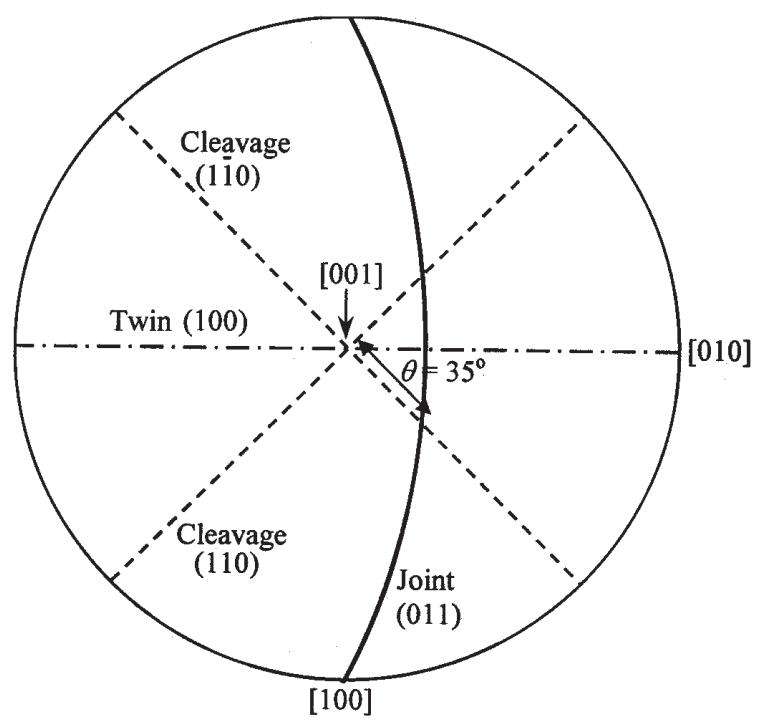

(b)

Figure 4. Stereographic projections showing three-dimensional crystallographic dispositions of the joint sets in olivine (a) and pyroxene (b).

thermal stresses because of its contrasting coefficient of thermal contraction with respect to the matrix. The stresses so generated may act radially as well as tangentially at the matrixphenocryst interface due to volume shrinkage (cf. Ramberg 1955). When these stresses exceed the tensile strength of the phenocryst, joints develop at its periphery in radial and concentric fashions (figure 2d). Understandably, the radial and tangential stresses decrease in magnitude towards the core of the phenocryst, and do not cause jointing at its interior. This, in other words, means that the joints that form in response to tensile stresses induced due to differential contraction of the matrix and the phenocryst are likely to be localized along its periphery as observed in the Rajmahal basalt (figures 2 and 3 ).

A cooling phenocryst may also develop thermal stresses due to non-uniform, intragranular contraction. Under specific rates of cooling conditions (discussed in the following section) the stresses may induce thoroughgoing joints within the phenocryst as observed in some samples of Rajmahal basalt (figures 2a, b, 3 and 5). In optically anisotropic crystals the thermal stresses may not be isotropic and the joints formed may have a preferred orientation with respect to the crystallographic directions of the mineral (figure 4).

Thermal stresses can develop in a cooling system only under specific conditions of spatial and temporal changes in its thermal state (Boley and Weiner 1960; Jaeger 1961, 1969). The following section presents a brief outline of the theory of development of thermal stresses to apprehend the physical basis of joint formation in a cooling system.

\section{Theoretical analysis of thermal stress}

For the theoretical analysis we shall first consider the general equation for the stress- strain relationship in a body that undergoes thermal changes. Let the temperature of the body be raised from $T_{1}$ to $T_{2}$. Assuming that the body is represented by a homogeneous, isotropic elastic material, the general constitutive equation relating stress and strain within the body is:

$$
\varepsilon_{i j}=\frac{1}{E}\left\{\sigma_{i j}+\nu\left(\sigma_{i j}-\delta_{i j} \sigma_{k k}\right)\right\}+\delta_{i j} \alpha T
$$

(Boley and Weiner 1960), where $i, j, k=x, y, z ; \delta_{i j}$ is Kronecker delta, wherein $\delta_{i j}=0$ and 1 for $i \neq j$ and $i=j$ respectively. $E$ is Young's modulus and $\nu$ is Poisson's ratio, $\alpha$ is the coefficient of thermal expansion and $T$ is the change in temperature, i.e. $\left(T_{2}-T_{1}\right)$. Now let us consider one of the strain and stress components from equation (1),

$$
\begin{aligned}
& \varepsilon_{x x}=\frac{1}{E}\left\{\sigma_{x x}-\nu\left(\sigma_{y y}+\sigma_{z z}\right)\right\}+\alpha T, \\
& \sigma_{x x}=\lambda e+2 \mu \varepsilon_{x x}-(3 \lambda+2 \mu) \alpha T
\end{aligned}
$$

where

$$
\begin{aligned}
\lambda= & \frac{\nu E}{(1+\nu)(1-2 \nu)}, \mu=\frac{E}{2(1+\nu)}, e=\varepsilon_{x x} \\
& +\varepsilon_{y y}+\varepsilon_{z z} .
\end{aligned}
$$



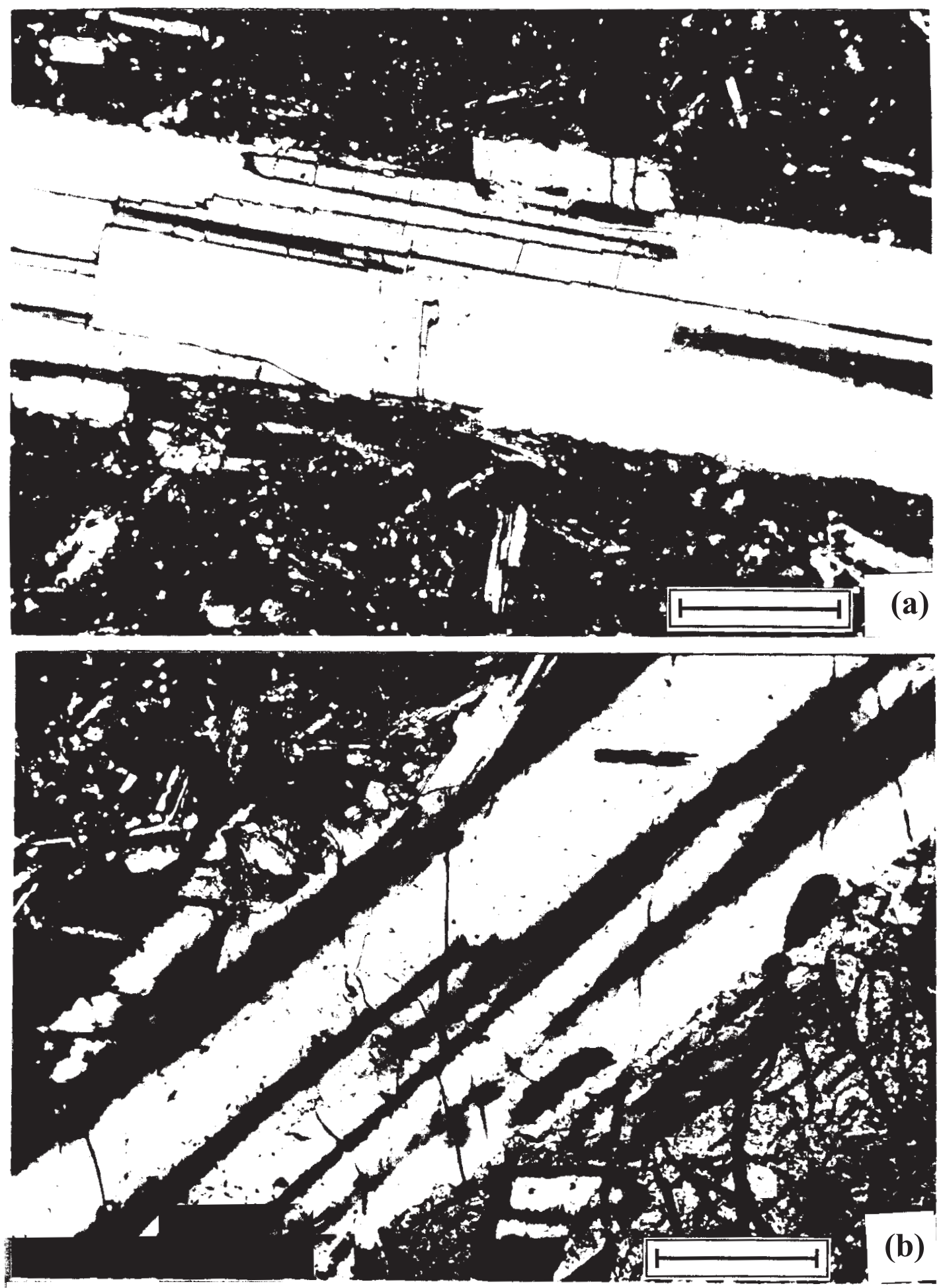

Figure 5. Joints in plagioclase laths. In (a) the joint set is at a right angle, whereas that in (b) is oblique to the length of the crystal. Crossed nicols. Scale bar $=0.08 \mathrm{~mm}$. 
Equation (3a) implies that thermal stresses would develop in the body when $\varepsilon_{x x}=\varepsilon_{y y}=\varepsilon_{z z}=0$, i.e. when the boundaries of the body are constrained. In that condition,

$$
\left(\sigma_{x x}\right)_{T}=-(3 \lambda+2 \mu) \alpha T,
$$

$\left(\sigma_{x x}\right)_{T}$ is the thermal stress in the body.

Now let us consider the condition in which thermal stress would generate in the body even when it is unconstrained. In a simply connected body with a non-uniform temperature distribution, the stress components and temperature gradients are related as:

$$
\begin{array}{r}
(1+\nu) \nabla^{2} \sigma_{i j}+\frac{\delta^{2} \theta}{\delta i \delta j}+\alpha E\left(\delta_{i j} \frac{1+\nu}{1-\nu} \nabla^{2} T\right. \\
\left.+\frac{\delta^{2} T}{\delta i \delta j}\right)=0
\end{array}
$$

where

$$
\begin{aligned}
\theta & =\sigma_{x x}+\sigma_{y y}+\sigma_{z z} \text { and } \\
\nabla^{2} & =\frac{\delta^{2}}{\delta x^{2}}+\frac{\delta^{2}}{\delta y^{2}}+\frac{\delta^{2}}{\delta z^{2}}
\end{aligned}
$$

(Boley and Weiner 1960).

Let us now find the thermal condition at which the body would be free from all stresses, i.e. $\sigma_{x x}=$ $\sigma_{y y}=\cdots \cdots \cdot=\sigma_{x y}=\sigma_{y z}=0$. Substituting these conditions in equation (4) we have,

$$
\begin{aligned}
\left(\frac{1+\nu}{1-\nu}\right) \nabla^{2} T+\frac{\delta^{2} T}{\delta x^{2}} & =0 \\
\left(\frac{1+\nu}{1-\nu}\right) \nabla^{2} T+\frac{\delta^{2} T}{\delta y^{2}} & =0 \\
\left(\frac{1+\nu}{1-\nu}\right) \nabla^{2} T+\frac{\delta^{2} T}{\delta z^{2}} & =0 \\
\alpha E \frac{\delta^{2} T}{\delta x \delta z} & =0 \\
\alpha E \frac{\delta^{2} T}{\delta x \delta y} & =0 \\
\alpha E \frac{\delta^{2} T}{\delta y \delta z} & =0 .
\end{aligned}
$$

Adding the first three equations in equation (5) we get,

$$
\nabla^{2} T=0 .
$$

Equation (6) reveals that thermal stresses will not develop in a body if the temperature distribution within it is harmonic, a condition which prevails when a body cools by steady state heat flow. Let us now find the condition of heat flow that would induce thermal stress within a body. We consider a thin plate of length and width many times its thickness with the heat flowing along the thickness, assuming that there is no significant temperature variation along length and width. Thus,

$$
\frac{\delta T}{\delta x}=\frac{\delta T}{\delta y}=0, \frac{\delta T}{\delta z}=f(z) .
$$

If the surface of the plate is free from traction, the stress components within the plate can be written as,

$$
\begin{aligned}
\sigma_{x x}= & \sigma_{y y}=\frac{\alpha E}{1-\nu}\left(-T+\frac{1}{2 h} \int_{-h}^{+h} T \mathrm{~d} z+\frac{3 z}{2 h^{3}}\right. \\
& \left.\int_{-h}^{+h} T z \mathrm{~d} z\right)
\end{aligned}
$$

(Boley and Weiner 1960). From the theory of heat flow we have

$$
K_{T}\left[\frac{\delta^{2} T}{\delta x^{2}}+\frac{\delta^{2} T}{\delta y^{2}}+\frac{\delta^{2} T}{\delta z^{2}}\right]+\frac{q}{\rho c}=\frac{\delta T}{\delta t}
$$

where $q$ is the rate of heat generation, $\rho$ is density, $c$ is specific heat, $\delta T / \delta t$ is the rate of change in temperature and $K_{T}$ is thermal conductivity. Now putting the boundary conditions (equation 7 ) in equation (9) we get,

$$
\frac{\delta^{2} T_{z}}{\delta z^{2}}=\frac{1}{K_{T}}\left(\alpha_{1}-\beta\right)
$$

where $\alpha_{1}=\frac{\delta T}{\delta t}$ and $\beta=\frac{q}{\rho c}$.

We can write equation (10) as

$$
\begin{aligned}
\frac{\delta}{\delta z}\left(\frac{\delta T_{z}}{\delta z}\right) & =\frac{1}{K_{T}}\left(\alpha_{1}-\beta\right) \\
\Rightarrow \quad \delta\left(\frac{\delta T_{z}}{\delta z}\right) & =\frac{1}{K_{T}}\left(\alpha_{1}-\beta\right) \delta z .
\end{aligned}
$$

Now solving the equation we can have,

$$
T_{z}=\frac{1}{2 K_{T}}\left(\alpha_{1}-\beta\right) z^{2}+C_{1} z+C_{2}
$$

where $C_{1}$ and $C_{2}$ are integration constants.

This is the general equation of the temperature distribution across the plate. The term $\alpha_{1}-\beta$ of equation (11) is non-zero and negative in the present study because the system of our consideration cools with time. In such a system the spatial temperature distribution would, therefore, be essentially non-linear, and equation (10) shows that the non-linearity will increase with increase in 
magnitude of $\alpha_{1}-\beta$. Now the constants $C_{1}$ and $C_{2}$ are to be determined satisfying the following boundary conditions.

$$
T_{z}=T_{m} \text { at } z=0 \text { and } T_{z}=T_{c} \text { at } z=h .
$$

Putting these values in equation (11),

$$
\begin{aligned}
C_{1}=T_{m} \text { and } C_{1}=-\frac{1}{h}[ & \left(T_{m}-T_{c}\right) \\
& \left.+\left(\frac{\alpha_{1}-\beta}{2 K_{T}}\right) h^{2}\right] .
\end{aligned}
$$

Now replacing $C_{1}$ and $C_{2}$ in equation (11),

$$
\begin{aligned}
T_{z} & =\left(\frac{\alpha_{1}-\beta}{2 K_{T}}\right) z^{2}-\frac{1}{h}\left[\left(T_{m}-T_{c}\right)\right. \\
& \left.+\left(\frac{\alpha_{1}-\beta}{2 K_{T}}\right) h^{2}\right] z+T_{m} . \\
\text { So, } T & =\left(T_{z}-T_{m}\right)=\left(\frac{\alpha_{1}-\beta}{2 K_{T}}\right) z^{2} \\
& -\frac{1}{h}\left[\left(T_{m}-T_{c}\right)+\left(\frac{\alpha_{1}-\beta}{2 K_{T}}\right) h^{2}\right] z .
\end{aligned}
$$

This equation can be written in a simple form

$$
T=\phi z^{2}+\psi z
$$

where $\phi=\frac{1}{2 K_{T}}\left(\alpha_{1}-\beta\right)$ and $\psi=-\frac{1}{h}\left[\Delta T+\phi h^{2}\right]$.

Substituting the equation (12) in equation (8),

$$
\begin{gathered}
\sigma_{x x}=\sigma_{y y}=\frac{\alpha E}{1-\nu}\left[\left(\phi z^{2}+\psi z\right)-\frac{1}{2 h} \int_{-h}^{+h}\left(\phi z^{2}\right.\right. \\
\left.+\psi z) \mathrm{~d} z-\frac{3 z}{2 h^{3}} \int_{-h}^{+h}\left(\phi z^{3}+\psi z^{2}\right) \mathrm{d} z\right] \\
\Rightarrow \sigma_{x x}=\sigma_{y y}=\frac{\alpha E}{1-\nu}\left[\phi z^{2}-\frac{\phi h^{2}}{3}\right] .
\end{gathered}
$$

At $\mathrm{z}=0$,

$$
\sigma_{x x}=\sigma_{y y}=-\frac{\alpha E}{1-\nu} \frac{\phi h^{2}}{3} .
$$

$\sigma_{x x}$ represents tensile stress, as $\phi$ is negative. The tensile stress will increase with increasing magnitude of $\phi$, which is a function of $\alpha_{1}-\beta$, indicating that the thermal stress will be significant to cause jointing only when the system cools rapidly.

\section{Experiments on thermal stress induced jointing}

A set of analogue model experiments was performed to study the influence of cooling rate on the

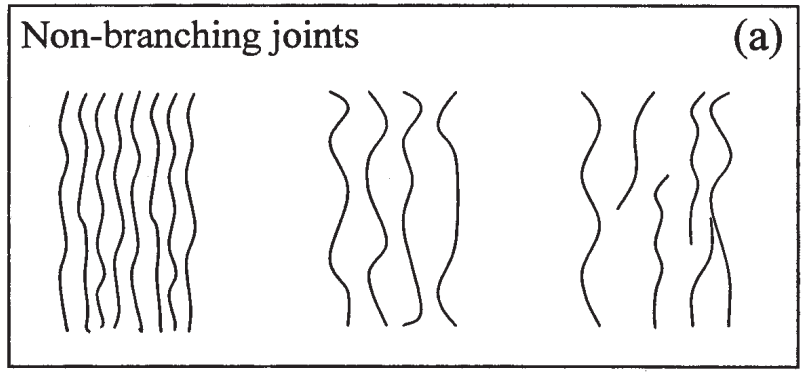

Branching joints

(b)
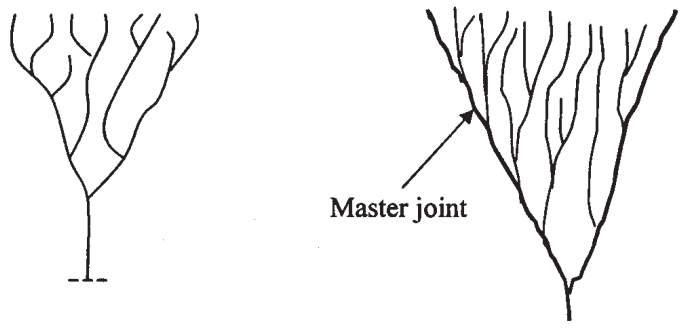

\section{Concentric joints}

(c)
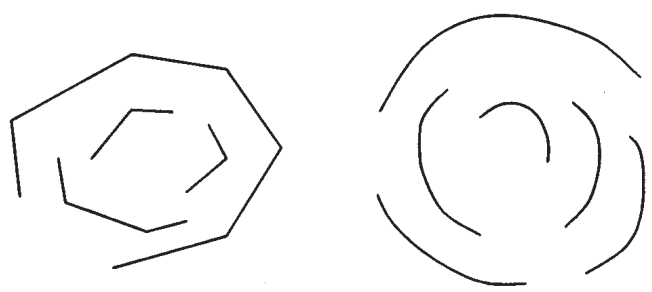

Figure 6. Different types of joint patterns observed in analogue model experiments.

development of micro-scale joints under thermal stresses. For experiments, model materials were chosen by trial so that

- it has a low melting temperature in order to keep the experimental procedure simple,

- the material is crystalline and optically anisotropic, and its crystallization behaviour is sensitive to the cooling condition, and

- the material has the property of developing cracks during quenching.

Two organic compounds were selected: (1) OPhenylenedianene $\left[\mathrm{C}_{6} \mathrm{H}_{4}(\mathrm{NH})_{2}\right.$, melting temperature $102^{\circ} \mathrm{C}-105^{\circ} \mathrm{C}$ ) and (2) 3,5-dinitro benzoic acid $\left[\mathrm{C}_{7} \mathrm{H}_{4} \mathrm{~N}_{2} \mathrm{O}_{6}\right.$, melting temperature $\left.205^{\circ} \mathrm{C}\right]$.

\subsection{Experimental method}

Experimental simulations were conducted in the following way. A small amount of powder of the 

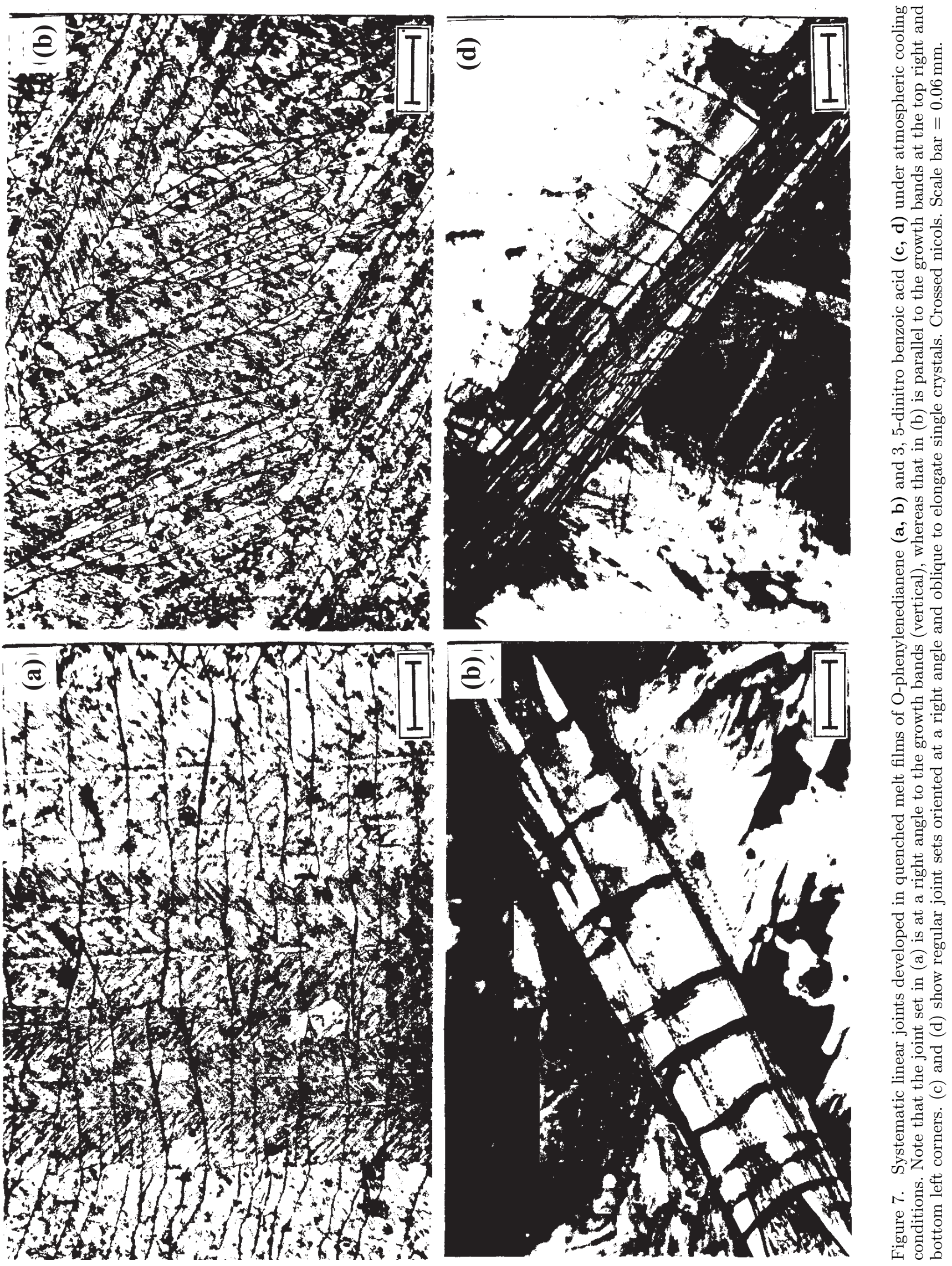

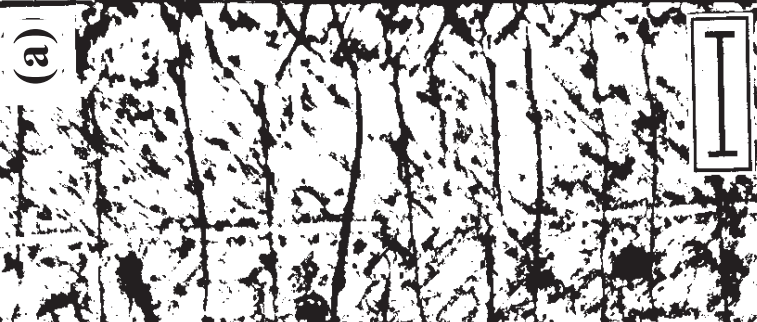
che

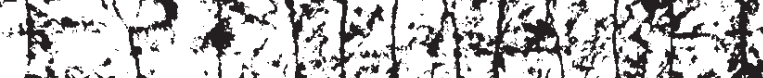
watom . (6) (3)

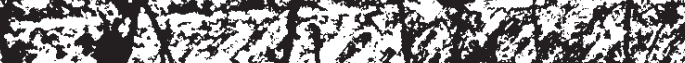

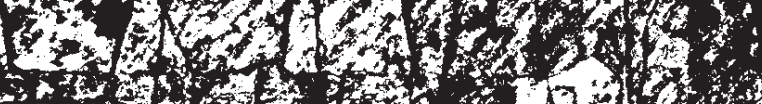

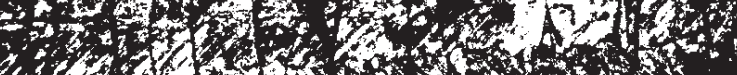

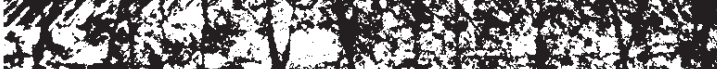

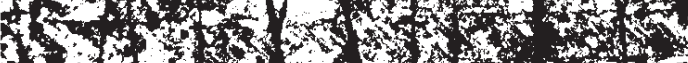

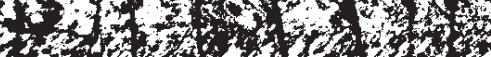

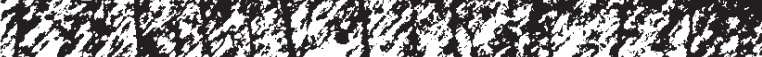

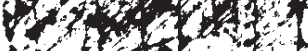

(x.)

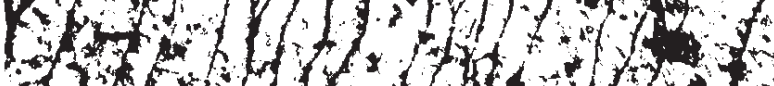

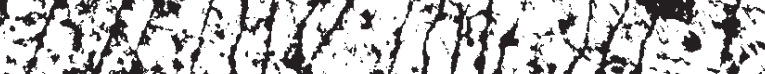

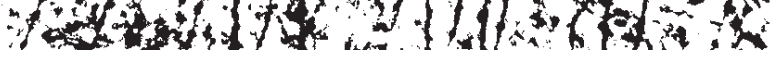



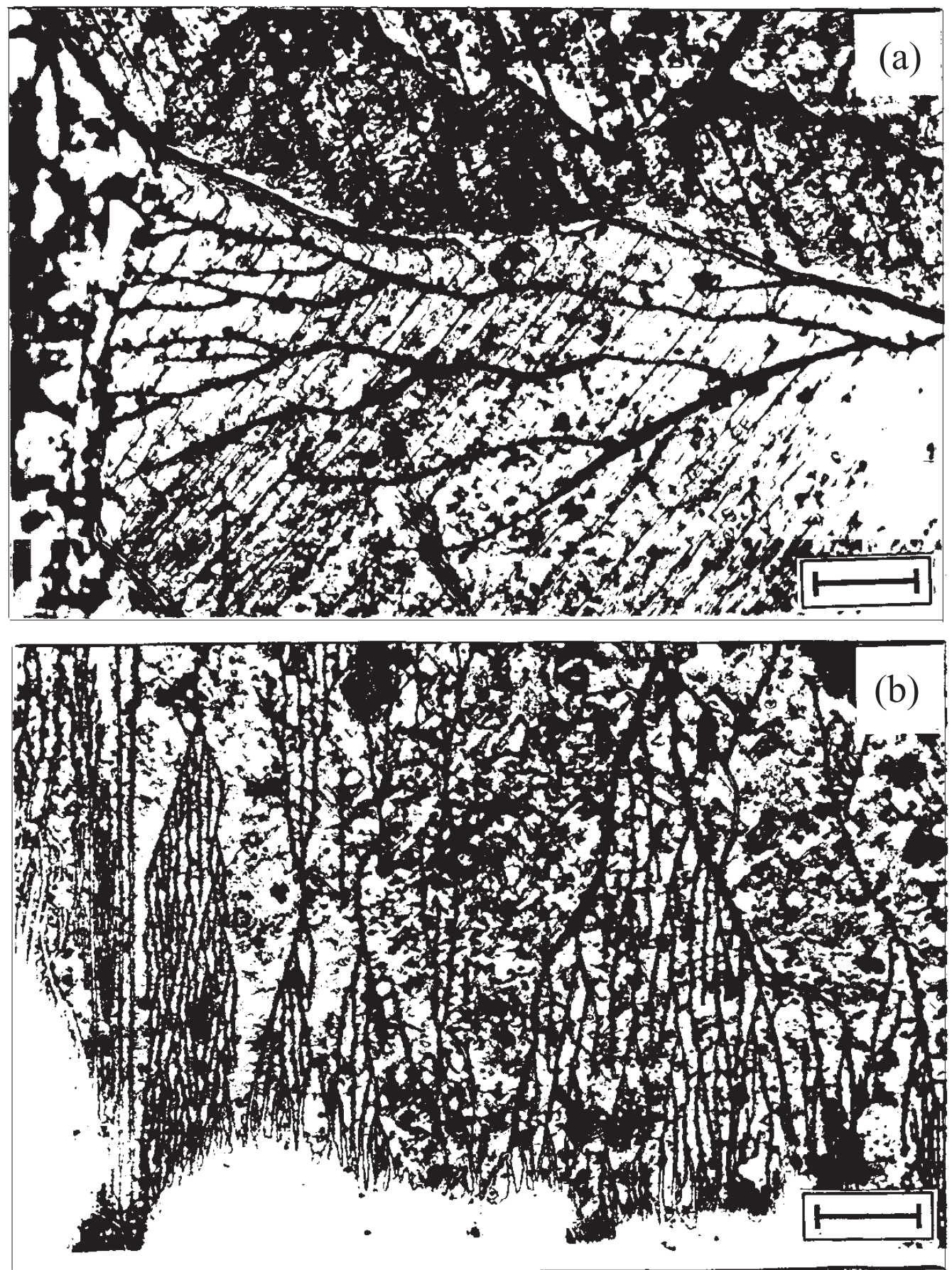

Figure 8. (Continued)

chosen organic material was taken on a glass slide. The lump of powder was then uniformly spread with a sharp knife to form a few grain thick veneer on the slide. The glass slide was heated in horizontal position on an electric heater in an atmospheric condition. Heating was continued till the powder underwent complete melting. The melt was then smeared to be a uniformly thick film. Quenching of the melt film was conducted under three conditions:
- at room temperature $\left(30^{\circ} \mathrm{C}\right)$,

- at normal refrigerator condition $\left(10^{\circ} \mathrm{C}\right)$ and

- at deep-freeze condition $\left(-2^{\circ} \mathrm{C}\right)$ to simulate different rates of cooling.

The quenched films were observed under a petrological microscope to study the effects of cooling conditions on the development of micro-scale joints. 


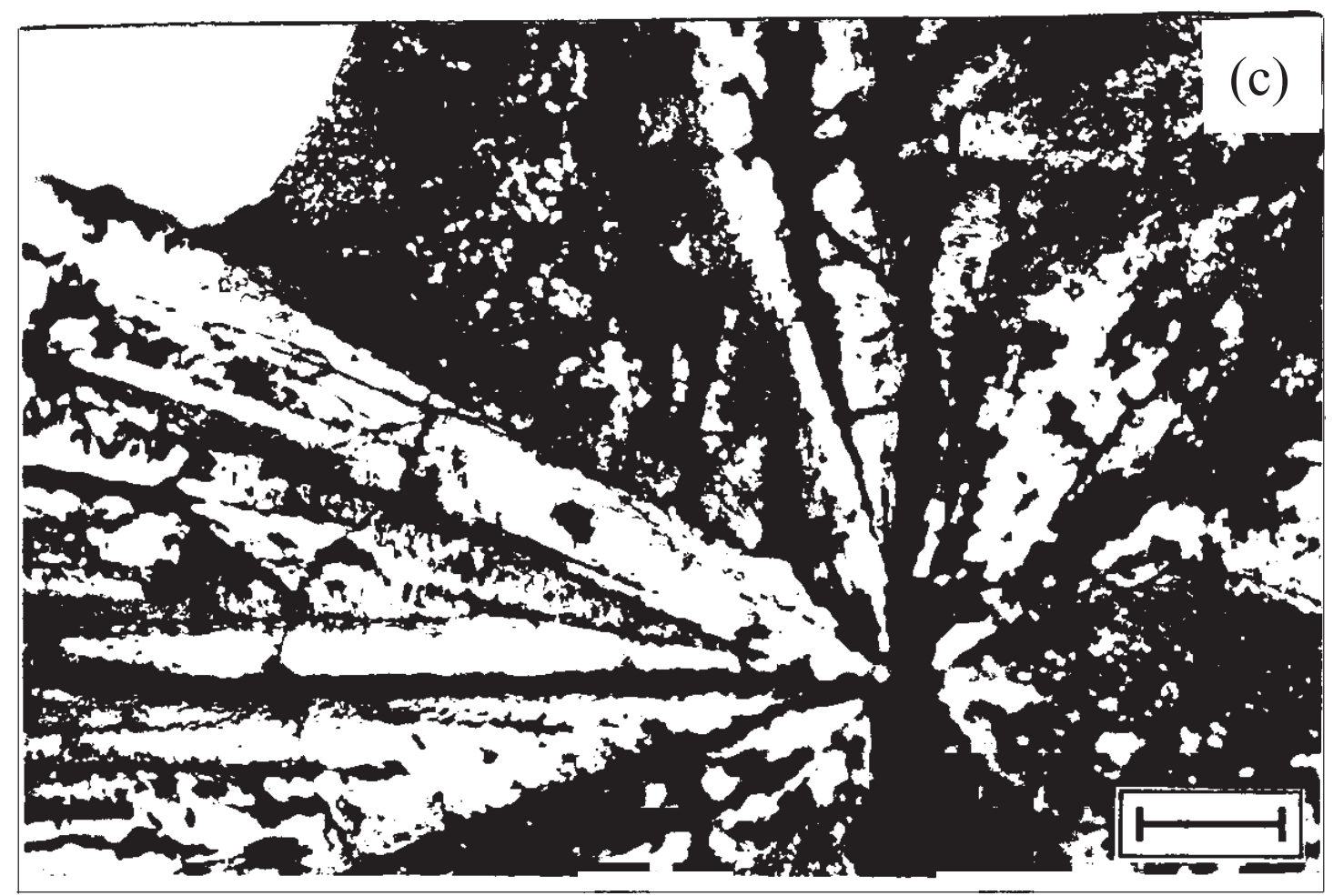

Figure 8. Branching (a, b) joints in O-phenylenedianene and concentric joints (c) in 3, 5-dinitro benzoic acid. The joints in (a) developed under normal freezing $\left(10^{\circ} \mathrm{C}\right)$ condition, whereas that in (b) and (c) developed under deep freezing $\left(-2^{\circ} \mathrm{C}\right)$ conditions. Note that the dendritic branching joint sets in (b) are bounded by two diverging master joints. Crossed nicols. Scale bar $=0.06 \mathrm{~mm}$.

\subsection{Experimental results}

Two major types of joints were noticed in the experiments: branching and non-branching (figures $6 \mathrm{a}$ and $\mathrm{b}$ ). The non-branching type includes sets of non-intersecting, quasi-linear as well as concentric joints (figures 6,7 and $8 \mathrm{c}$ ). The joints within a set are generally uniformly spaced. Branching joints show typical dendritic pattern of arrangement with individual joints showing progressive branching (figure 8a). Individual sets of branching joints originate from a point and widen along the crack propagation direction. In some cases subsidiary joints originate from two diverging linear, master joints defining the boundaries of the set (figure 8b). Within such a set, the subsidiary joints also show progressive branching along the crack propagation direction.

Non-branching linear joints developed during cooling of the melt film under atmospheric condition. Within a set, the joints are systematic, regularly spaced. They may be oriented parallel, oblique or at right angles to the length of growth bands or single laths of large crystals (figures $7 \mathrm{c}$ and $\mathrm{d}$ ). The joints developed in crystal laths strongly resemble those observed within feldspar phenocrysts of the Rajmahal basalt (figure 5a).
Branching joints developed both under (1) normal refrigeration condition $\left(10^{\circ} \mathrm{C}\right)$ and $(2)$ deepfreezing conditions $\left(-2^{\circ} \mathrm{C}\right)$ (figures $8 \mathrm{a}$ and $\mathrm{b}$ ). However, the joint sets formed under deep-freezing conditions are usually bounded by major joints in contrast to that formed under normal refrigeration conditions.

Concentric joints typically develop under deepfreezing conditions. These joints are usually associated with radially grown crystals and are concentric about the point from which the crystals radiate (figure $8 \mathrm{c}$ ). The present experiments did not produce radial joints, as observed in quenched rocks (figures $2 \mathrm{c}$ and $\mathrm{d}$ ). This is probably due to fiber-like crystal habit of the material chosen for the experiments.

\section{Discussion and conclusions}

The natural and experimental observations indicate that micro-scale joints may develop in a cooling system in response to thermal stresses. The theoretical analysis reveals that the magnitude of the thermal stress depends on the rate of cooling, which may have resulted into different modes of jointing in experiments performed under different cooling conditions. Varying cooling rates were 
simulated in the experiments by imposing different ambient temperatures, as mentioned in section 4.1. When the rate of cooling was low, linear, nonbranching joints were abundant and occurred as a regular set. With the increase in the rate of cooling branching type of joints dominated over the linear joints. Understandably, the mechanics of crack propagation in the development of branching and non-branching joints are different. Therefore, to understand the transition between the two modes of jointing we need to consider the changes in the crack mechanics in response to changing cooling conditions.

The nature of crack propagation depends on an important factor known as stress intensity factor $(K)$. For a two-dimensional crack the stress intensity factor is given as

$$
K=Y \sigma_{r}(\pi l)^{1 / 2}
$$

(Atkinson 1987), where $\sigma_{r}$ is the bulk applied stress, $Y$ is the numerical modification factor to account for crack geometry, loading condition and edge effects and $l$ is half the crack length (for penny-shaped, internal cracks). There exists a critical value of $K$ below which the crack is stable. Once the critical value is reached the crack may propagate catastrophically at the speed of sound in the media (figure 9; p 9, Atkinson 1987). However, it has been observed in experiments on a wide range of materials that significant crack growth can also occur at values of $K$ far below the critical value. This is known as sub critical crack growth. The velocity of crack propagation, $v$ holds a definite relationship with $K$ as $v=f(K)$ (figure 9). The sub critical crack velocity increases as $K$ is increased until a critical value $K_{c}$ is attained. At this critical value the crack propagates catastrophically and accelerates rapidly. Crack branching may occur during such dynamic growth when $K$ is much above the critical value $K_{c}$. It may thus be inferred that the non-branching joints produced in the experiments developed under sub-critical conditions (at lower rates of cooling), whereas the branching joints reflect supercritical mode of crack propagation (at higher rates of cooling).

It should be noted that the theoretical and experimental models do not exactly simulate natural rock systems. Rocks are texturally heterogeneous and are made up of different anisotropic mineral constituents, while the theoretical analysis assumes homogeneous isotropic material and the experimental models involve single-phase material. Hence the theoretical and experimental analyses do not fully explain the fracture behaviour in natural examples. But they do provide some guidelines about the pattern of thermal stress in cooling systems and the resultant joints. However, the

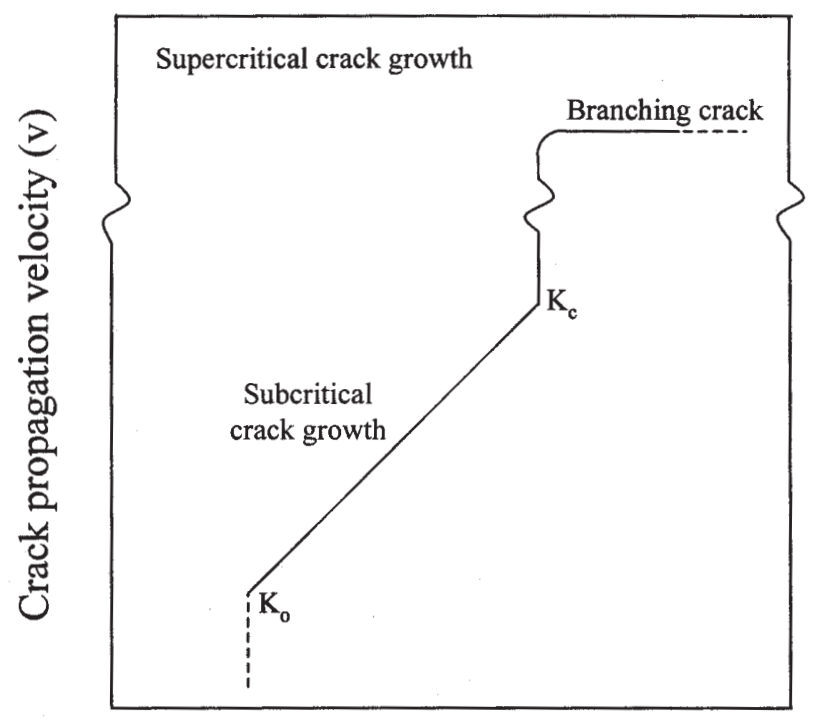

Stress intensity factor (K)

Figure 9. Diagram showing variation of crack propagation velocity as a function of stress intensity factor (after Atkinson 1987). The curve delineates fields of different modes of crack growth. $K_{o}$ is the stress intensity factor below which an incipient crack remains stable. $K_{c}$ is the stress intensity factor above which an incipient crack grows catastrophically with accelerating velocities (supercritical crack growth) leading to branching of cracks. Between $K_{0}$ and $K_{c}$ cracks grow with uniform velocities (sub-critical crack growth).

controls on jointing in quenched natural rocks are more complex than envisaged in the models.

The principal outcome of the present study can be summarized along the following points:

- The development of cooling joints will be favored under strongly non-linear temperature distributions in space and under conditions of unsteady cooling.

- Micro-scale cooling joints in optically anisotropic minerals may be systematic with definite crystallographic orientations.

- The geometry and pattern of joints depend on the cooling rate. Branching type of joints generate when the cooling rate is high whereas regularly spaced linear joints form under slow rate of cooling.

\section{Acknowledgements}

I wish to thank two anonymous reviewers for critical comments that greatly contributed to the improvement of the paper. I am grateful to Dr. S K Nag for providing me samples of the Rajmahal volcanics. The financial assistance from UGC and CSIR, India, is gratefully acknowledged. The Jadavpur University provided the infrastructural facilities. 


\section{References}

Atkinson B K 1987 Introduction of fracture mechanics and its geophysical applications; In Fracture mechanics of rocks (ed. B K Atkinson) (London: Academic Press) pp $1-26$

Ball V 1877 Geology of Rajmahal; Mem. Geol. Surv. India 13 155-248

Boley B A and Weiner J H 1960 Theory of thermal stresses (New York: John Wiley \& Sons) 585 pp

Harley S L 1989 The origin of granulites: a metamorphic perspective; Geological Magazine 126 215-331

Jaeger J C 1961 The cooling of irregularly shaped igneous bodies; Am. J. Sci. 259 721-734

Jaeger J C 1969 Elasticity, fracture and flow with engineering and geological application (London: Methuen)
Ji S, Zhao P and Saruwatari K 1997 Fracturing of garnet crystals in anisotropic rocks during Uplift; J. Struc.l Geol. $19603-620$

Macdonald G A 1968 Form and structures of extrusive Basaltic rocks (Intersciences Publication).

Moore H F and Sibson R H 1978 Experimental thermal fragmentation in relation to seismic faulting; Tectonophysics 49 T9-T17

Peck D L and Minakami T 1968 The formation of columnar joints in the upper part of Kilaueau Lava Lakes, Hawaii; Bull. Geol. Soc. Am. 79 1151-1166

Ramberg H 1955 Natural and experimental boudinage and pinch-and-swell structures; J. Geol. 63 512-526

Spry A 1962 The origin of columnar jointing particularly in basaltic flows J. Geol. Soc. Aust. 8 191216

MS received 5 October 2000; revised 15 July 2001 